\title{
Risk stratification and medical therapy of pulmonary arterial hypertension
}

\author{
Nazzareno Galiè ${ }^{1}$, Richard N. Channick², Robert P. Frantz ${ }^{3}$, Ekkehard Grünig ${ }^{4}$, \\ Zhi Cheng Jing ${ }^{5}$, Olga Moiseeva ${ }^{6}$, loana R. Preston ${ }^{7}$, Tomas Pulido $^{8}$, \\ Zeenat Safdar ${ }^{9}$, Yuichi Tamura ${ }^{10}$ and Vallerie V. McLaughlin ${ }^{11}$
}

Number 6 in the series

"Proceedings of the 6th World Symposium on Pulmonary Hypertension" Edited by N. Galiè, V.V. McLaughlin, L.J. Rubin and G. Simonneau

\begin{abstract}
Affiliations: 'Dept of Experimental, Diagnostic and Specialty Medicine (DIMES), Alma Mater Studiorum, University of Bologna, Bologna, Italy. ${ }^{2}$ Pulmonary and Critical Care Division, Massachusetts General Hospital, Harvard Medical School, Boston, MA, USA. ${ }^{3}$ Dept of Cardiovascular Diseases, Mayo Clinic, Rochester, MN, USA. ${ }^{4}$ Pulmonary Hypertension Center, Thoraxklinic at Heidelberg University Hospital, Heidelberg, Germany. ${ }^{5}$ State Key Lab of Cardiovascular Disease, FuWai Hospital and Key Lab of Pulmonary Vascular Medicine, Chinese Academy of Medical Sciences and Peking Union Medical College, Beijing, China. ${ }^{6}$ Non-Coronary Heart Disease Dept, Almazov National Medical Research Centre, St Petersburg, Russian Federation. ${ }^{7}$ Tufts University School of Medicine, Pulmonary, Critical Care and Sleep Division, Tufts Medical Center, Boston, MA USA. ${ }^{8}$ Cardiopulmonary Dept, National Heart Institute, La Salle University, Mexico City, Mexico. ${ }^{9}$ Pulmonary, Critical Care Division, Houston Methodist Hospital, Weill Cornell College of Medicine, Houston, TX, USA. ${ }^{10}$ Dept of Cardiology, International University of Health and Welfare School of Medicine, Tokyo, Japan.

${ }^{11}$ Cardiovascular Medicine, The University of Michigan, Ann Arbor, MI, USA.
\end{abstract}

Correspondence: Nazzareno Galiè, Dept of Experimental, Diagnostic and Specialty Medicine (DIMES), Alma Mater Studiorum, University of Bologna, Via Massarenti 9, 40138 Bologna, Italy. E-mail: nazzareno.galiedunibo.it

@ERSpublications

State of the art and research perspectives on medical therapy of pulmonary arterial hypertension, including treatment algorithm http://ow.ly/4UkJ30md5GS

Cite this article as: Galiè N, Channick RN, Frantz RP, et al. Risk stratification and medical therapy of pulmonary arterial hypertension. Eur Respir J 2019; 531801889 [https://doi.org/10.1183/13993003.018892018].

ABSTRACT Pulmonary arterial hypertension (PAH) remains a severe clinical condition despite the availability over the past 15 years of multiple drugs interfering with the endothelin, nitric oxide and prostacyclin pathways. The recent progress observed in medical therapy of $\mathrm{PAH}$ is not, therefore, related to the discovery of new pathways, but to the development of new strategies for combination therapy and on escalation of treatments based on systematic assessment of clinical response. The current treatment strategy is based on the severity of the newly diagnosed PAH patient as assessed by a multiparametric risk stratification approach. Clinical, exercise, right ventricular function and haemodynamic parameters are combined to define a low-, intermediate- or high-risk status according to the expected 1-year mortality. The current treatment algorithm provides the most appropriate initial strategy, including monotherapy, or double or triple combination therapy. Further treatment escalation is required in case low-risk status is not achieved in planned follow-up assessments. Lung transplantation may be required in most advanced cases on maximal medical therapy. 


\section{Introduction}

Pulmonary arterial hypertension (PAH) remains a severe clinical condition despite the publication of 41 randomised clinical trials (RCTs) in the past 25 years and the regulatory approval of multiple drugs active by four routes of administration (i.v., s.c., oral and inhaled) [1,2]. Currently approved therapies target three main pathways important in endothelial function: the prostacyclin and nitric oxide (NO) pathways, which are underexpressed in PAH patients, and the endothelin pathway, which is overexpressed in PAH patients (see the Task Force article by Humbert et al. [3] in this issue of the European Respiratory Journal). This imbalance in vasoactive mediators plays a critical role in the development and progression of the obstructive proliferative pathological changes of the distal pulmonary arteries [3], which, when untreated, will lead to heart failure and premature death (see the Task Force article by VONK NoORDEGRAAF et al. [4] in this issue of the European Respiratory Journal). Prostacyclin analogues (PCAs) and prostacyclin receptor agonists, phosphodiesterase type 5 inhibitors (PDE5is) and guanylate cyclase stimulators, and endothelin receptor antagonists (ERAs) are intended to correct the dysfunction of the prostacyclin, NO and endothelin pathways, respectively. Interestingly, drugs targeting the three pathways were already approved and included in the treatment algorithm for PAH patients proposed in 2003 at the 3rd World Symposium on Pulmonary Hypertension (WSPH) held in Venice, Italy [5]. The progress observed in medical therapy of PAH patients over the past 15 years is not, therefore, related to the discovery of new pathways, but to the evolution and testing of new drugs and strategies for combination therapy, and on escalation of treatments based on systematic assessment of clinical response [1, 2]. In fact, in the 2015 European Society of Cardiology (ESC)/European Respiratory Society (ERS) pulmonary hypertension (PH) guidelines the treatment strategy was intimately linked to the baseline severity of the newly diagnosed PAH patient and recommendations for subsequent treatment escalation were founded on the patient's conditions after a pre-specified period of therapy $[1,2]$. Both the baseline assessment and the treatment response were based on a multiparametric approach to stratify the patients in low-, intermediate- or high-risk groups for 1-year mortality. The "risk" table included clinical, functional, exercise, right ventricular function and haemodynamic parameters.

This central connection between methodical risk assessment and treatment strategy in PAH patients has been recently validated by retrospective analyses of three independent registries, showing a clear prediction of survival or event-free survival based on this multiparametric approach at baseline and at follow-up [6-9].

This article will provide an updated analysis of risk stratification and its relationship with different treatment strategies available for $\mathrm{PAH}$ patients, including general measures, supportive therapies, monotherapy, initial and sequential combination therapy, and interventional therapies.

\section{Risk stratification}

The assessment of the prognosis of patients with $\mathrm{PAH}$ has been considered an important part of care since the publication of the first US National Institutes of Health idiopathic PAH (IPAH) registry nearly three decades ago [10]. Over time, different baseline and follow-up parameters, including clinical, functional, exercise, non-invasive and invasive variables, have been utilised individually or combined in formulas or calculators to predict outcome: the French Pulmonary Hypertension Network (FPHN) registry risk equation [11, 12], the PH connection equation [13, 14], the Scottish composite score [15], the US Registry to Evaluate Early and Long-term PAH Disease Management (REVEAL) risk equation [16] and risk score [17, 18], and the 2015 ESC/ERS PH guidelines risk table $[1,2]$. Table 1 shows the characteristics of four registries testing the PAH risk stratification strategy of the REVEAL score and of the 2015 ESC/ERS PH guidelines risk table [6-9, 17-19].

The REVEAL equation [16] and the subsequent score [17, 18], derived from a cohort of $2716 \mathrm{PAH}$ patients and using 12 modifiable and non-modifiable parameters measured at baseline, provided the 12-month likelihood of survival (five strata) in incident and prevalent IPAH and associated PAH patients. If utilised at follow-up, the equation can predict outcome at 1 additional year [18]. The risk score calculator was validated internally in 504 newly diagnosed PAH patients, externally in registries and in clinical trials datasets $[20,21]$. Survival up to 5 years has been reported according to baseline REVEAL score data, but not at follow-up reassessment [22]. REVEAL survival up to 5 years has also been provided for a subgroup of 1426 patients and based only on repeated high versus low brain natriuretic peptide (BNP) plasma level assessments [23]. The REVEAL registry also demonstrated the prognostic value of renal dysfunction at baseline and follow-up measurements of estimated glomerular filtration rate (eGFR) [24].

The REVEAL 2.0 risk score calculator is a refinement of the original REVEAL risk score calculator; it includes all-cause hospitalisations within the previous 6 months and eGFR, both of which have been shown to impact mortality $[24,25]$. 
TABLE 1 Summary of four registries assessing risk scores

\section{REVEAL [17-19] Swedish PAH Register [6] COMPERA [7] French Pulmonary}

Hypertension Network [8]

\begin{tabular}{lcccc}
\hline Required variables $\mathbf{n}$ & $12-14$ & 8 & 8 & 4 \\
Patients at baseline $\mathbf{n}$ & 2716 & 530 & 1588 & 1017 \\
Patients at follow-up $\mathbf{n}$ & 2529 & 383 & 1094 & 1017 \\
Associated PAH included & Yes & Yes & Yes & No \\
Definition of low risk & $\leqslant 6$ REVEAL score & $<1.5$ average score & $<1.5$ average score & $3-4$ out of 4 low-risk criteria \\
1-year mortality by risk group & $\leqslant 2.6 / 7.0 / \geqslant 10.7$ & $1.0 / 7.0 / 26.0$ & $2.8 / 9.9 / 21.2$ & $1.0 /$ NA/13.0-30.0 \\
$\quad$ (low/intermediate/high) \% & & & &
\end{tabular}

PAH: pulmonary arterial hypertension; NA: not available. " : incident patients only.

The REVEAL 2.0 risk score calculator (14 variables) has been compared [19] with the strategies utilised in the FPHN registry [8] and in the Prospective Registry of Newly Initiated Therapies for Pulmonary Hypertension (COMPERA) registry [7]. In this experience the data showed that, based on the 12-month mortality, the correspondences between the low-, intermediate- and high-risk groups as defined by the 2015 ESC/ERS PH guidelines and the REVEAL 2.0 calculator (14 variables) were as follows: low risk=REVEAL score $\leqslant 6$, intermediate risk=REVEAL score 7 and 8 , and high risk=REVEAL score $\geqslant 9$. The authors propose a more discriminating risk stratification provided by the REVEAL score, although it is not clear how this translates to the approach to treatment [7].

The limitations of the REVEAL score include the relatively short prediction period ( 1 year) when assessed at follow-up and the large number of variables required (from 12 to 14 variables). Simplified versions of the REVEAL score utilising high-yield variables seem to have a similar predictive value as the original version [26].

The 2015 ESC/ERS PH guidelines have recommended a flexible approach to PAH patient risk assessment: using a multidimensional stratification according only to modifiable clinical, functional, exercise, biochemical, echocardiographic and haemodynamic variables with known prognostic significance (ESC/ERS PH guidelines Table 13 Risk assessment in PAH). Patients were categorised as low, intermediate or high risk based on expected 1-year mortality [1,2]. Recently, a retrospective analysis of three major registries (total of 3135 patients) provided an independent validation of this approach and showed a clear difference in 5-year survival or transplantation-free survival, depending on risk stratification category at both baseline and first follow-up [6-8]. In addition, post hoc analysis of the SERAPHIN haemodynamic substudy has shown a reduction in the morbidity and mortality end-point if low-risk haemodynamics thresholds included in the 2015 ESC/ERS PH guidelines were reached after 6 months of treatment with macitentan [27].

Interestingly, the risk stratification strategies have varied significantly among the registry studies: in the Swedish PAH Registry (SPAHR) [6] and COMPERA [7] studies (both including IPAH and associated PAH patients), individual risk was calculated at baseline and at the first follow-up by assigning a score of 1,2 or 3 to each criterion (1=low risk, $2=$ intermediate risk and $3=$ high risk according with the 2015 ESC/ERS PH guidelines) and rounding to the mean of the available variables. In the FPHN registry [8], risk assessment was performed in incident IPAH patients according to the presence of four low-risk criteria: World Health Organization (WHO)/New York Heart Association Functional Class (FC) I or II, 2) 6-min walk distance (6MWD) $>440 \mathrm{~m}, 3$ ) right atrial pressure (RAP) $<8 \mathrm{mmHg}$ and 4) cardiac index $\geqslant 2.5 \mathrm{~L} \cdot \mathrm{min}^{-1} \cdot \mathrm{m}^{-2}$. Patients were classified according to the number of low-risk criteria present at baseline (i.e. at the time of PAH diagnosis) or at the time of re-evaluation. As exploratory analyses, the additive value of $\mathrm{BNP}<50 \mathrm{ng} \cdot \mathrm{L}^{-1}$ or N-terminal pro-BNP (NT-proBNP) $<300 \mathrm{ng} \cdot \mathrm{L}^{-1}$ plasma levels or mixed venous oxygen saturation $\left(\mathrm{SvO}_{2}\right)>65 \%$ as low-risk criteria was assessed in the subsets of patients for whom these data were available.

Recently, the FPHN non-invasive risk assessment strategy using three dichotomised low-risk criteria (FC, 6MWD and NT-proBNP or BNP plasma levels) has been applied to the COMPERA cohort at baseline and at the first follow-up: the authors conclude that the FPHN risk assessment strategy provides a more accurate identification of patients with an excellent long-term survival than the approach of averaging risk scores [9].

Interestingly, the variables with the highest yield in the registriy analyses are similar, i.e. FC, 6MWD, NT-proBNP or BNP plasma levels, cardiac index, RAP and $\mathrm{SvO}_{2}[6-8]$. These variables are appropriate at 
both baseline and first follow-up, and the fulfilment of low-risk criteria in three or four parameters represents a clinical response to the treatment that portends a good prognosis [8, 9]. A new risk stratification strategy based on four criteria and using these six variables has recently been proposed [28].

The limitations of the 2015 ESC/ERS PH guidelines risk table are related to the presence of "overlap patients" with prognostic parameters belonging to more than one risk designation $[1,2]$. This problem has been addressed in the registry analyses with both the "score and average" method of the SPAHR and COMPERA registries and the "low-risk focused" method of the FPHN study. These methods may prove to be difficult to utilise in clinical practice, particularly for the exact distinction between intermediate- and high-risk status in individual patients. In addition, the simplified approach does not include non-modifiable or partially modifiable prognostic parameters such as age, sex, PAH type and comorbidities (renal insufficiency, diabetes mellitus, coronary artery diseases, etc.).

There are several limitations present in all risk assessment methods, including the retrospective nature of the validating analyses even when applied to prospective observational registries. In addition, data collection was not standardised in all published registries, and significant missing data and numbers of patients lost to follow-up were reported. Other important prognostic variables such as echocardiographic, cardiac magnetic resonance imaging and cardiopulmonary exercise test data were not collected systematically or analysed. Life-threatening complications such as haemoptysis, pulmonary artery aneurismal dilatation with chest organ compression, arrhythmias, etc., are not included in the current risk stratification tools. The exact influence of these parameters on the risk level designation and on the consequent treatment decisions need to be clarified in future and prospective studies. These data should be considered as part of a comprehensive risk assessment strategy which, of course, should also include clinical judgement [29].

\section{Clinical trials in PAH}

Figure 1 shows the time-course of the 41 RCTs performed in $9061 \mathrm{PAH}$ patients and published so far [30-70]. 21 RCTs tested monotherapy versus placebo, 18 RCTs included patients already treated and tested sequential combination therapy versus background therapy plus placebo, and finally two RCTs enrolled treatment-naive patients and tested initial monotherapy versus initial double combination therapy. The different treatment strategies adopted and compared, and the diverse background therapies of enrolled $\mathrm{PAH}$ patients, has allowed evidence to be collected on efficacy and safety for the multiplicity of conditions encountered in clinical practice.

An important evolution in PAH RCT design is the shifting of the primary end-point from a short-term correlate such as 6MWD to a long-term true clinical efficacy measure such as clinical worsening [60, 68, 69] or clinical failure [67]. Interestingly, this change in strategy was recommended by the Task Force on Clinical Trials Design at the 4th WSPH held in Dana Point, CA, USA, in 2008 [71]. This shift has supported an increase in the level of evidence of the efficacy of the tested PAH drugs according with the scale adopted by experts $[72,73]$.

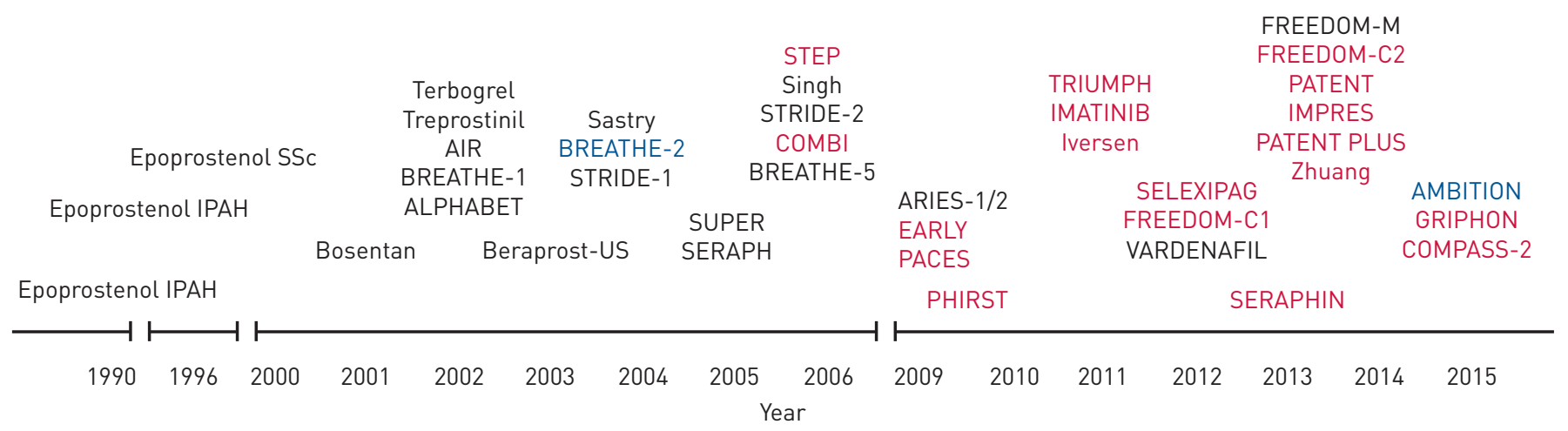

RCTs on monotherapy versus placebo or versus monotherapy ( $n=21$ )

RCTs on monotherapy and/or sequential combination versus placebo $(n=18)$

$\mathrm{RCTs}$ on initial combination versus monotherapy $(\mathrm{n}=2)$

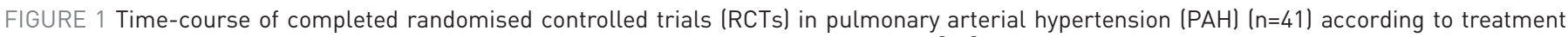
strategy. SSc: systemic sclerosis; IPAH: idiopathic PAH. Reproduced and modified from [70] with permission. 
The effect of PAH drugs on mortality was explored in a meta-analysis of 3839 patients enrolled in 25 RCTs testing monotherapy versus placebo in treatment-naive patients and reporting a risk reduction of $44 \%(\mathrm{p}=0.016)$ in the 14 weeks of the average treatment comparison time [70, 74]. An additional meta-analysis was performed in 4095 patients enrolled in 17 RCTs that compared sequential combination therapy with monotherapy [75]: in this analysis, sequential therapy was associated with a significant risk reduction for clinical worsening $(-35 \%$; $\mathrm{p}<0.0001)$, but not mortality $(-14 \% ; \mathrm{p}=0.09)$. The potential reasons for the lack of apparent mortality benefit include reduced statistical power of this meta-analysis for mortality as well as an overall reduced number of fatal events linked also to a short duration of the treatment comparison period [75].

In summary, based on global experience collected in the RCTs on PAH patients, the following comments can be proposed:

- In treatment-naive PAH patients, initial monotherapy is able to improve exercise capacity, haemodynamics and outcome compared with untreated patients [70, 74].

- In treatment-naive and newly diagnosed (incident) PAH patients, initial combination therapy is able to improve symptoms, exercise capacity and outcome compared with initial monotherapy [67, 76].

- In already treated (prevalent) PAH patients, sequential combination therapy is able to improve exercise capacity, haemodynamics and outcome compared with patients continuing with their background therapy $[60,69,75]$.

\section{General measures and supportive therapy}

No major advances have been reported on general measures and supportive therapy since the publication of the 2015 ESC/ERS PH guidelines, and the recommendations included in the 2015 ESC/ERS PH guidelines Table 16 Recommendations for general measures and Table 17 Recommendations for supportive therapy can be referred to $[1,2]$. In particular, oral anticoagulant therapy is not recommended in associated forms of PAH, while in IPAH, heritable PAH (HPAH) and drug-induced PAH the data on efficacy is more conflicting. Therefore, in this subgroup, the decision about anticoagulation has to be made on a case-by-case basis after an individual risk-benefit analysis. The 2015 ESC/ERS PH guidelines suggest that PAH patients should be advised to be active within symptom limits, but to avoid excessive physical exertion if this causes symptoms. Physically deconditioned patients who are stable on targeted medication are also advised to undertake supervised exercise training. Recently, two further RCTs and meta-analyses have been published in this regard, confirming the positive effect of training in PAH [77, 78].

\section{Treatment algorithm}

The recommended treatment algorithm for PAH patients is shown in figure 2.

The PAH treatment algorithm does not apply to patients in other clinical groups, and in particular it does not apply to patients with $\mathrm{PH}$ associated with group 2 (left heart disease) or group 3 (lung diseases). In addition, the different treatments have been evaluated by RCTs mainly in IPAH, HPAH, PAH due to drugs and in PAH associated with connective tissue disease, with Eisenmenger syndrome or with corrected congenital heart disease. The haemodynamic inclusion criteria in the majority of the RCTs were as follows: pulmonary arterial wedge pressure $\leqslant 15 \mathrm{mmHg}$, mean pulmonary arterial pressure $\geqslant 25 \mathrm{mmHg}$ and pulmonary vascular resistance $>3$ Wood Units ( $>5$ Wood Units in some RCTs). It is not clear if the efficacy/safety ratio of the PAH drugs is favourable when used in patients not fulfilling the above criteria. There is insufficient evidence to make recommendations in group 5 patients.

Since the release of the 2015 ESC/ERS PH guidelines no new RCTs leading to the approval of new PAH treatments have been published; we refer to the tables of these guidelines for the classes of recommendations and the level of evidence of the approved $\mathrm{PAH}$ treatments $[1,2]$. In particular, the guidelines tables of interest are: Table 1 Classes of recommendations, Table 2 Level of evidence, Table 19 Recommendations for efficacy of drug monotherapy, Table 20 Recommendations for efficacy of initial drug combination therapy, Table 21 Recommendations for efficacy of sequential drug combination therapy, and Table 22 recommendations for efficacy of intensive care unit management, balloon atrial septostomy and lung transplantation. Amendments to these tables are required only for approvals granted by regulatory agencies after the 2015 ESC/ERS PH guidelines as follows: selexipag has been approved by the European Medicines Agency in patients with WHO FC II either as double or triple combination with an ERA and/ or a PDE5i, or as monotherapy in patients who are not candidates for these therapies.

The 2015 ESC/ERS PH guidelines tables provide the necessary evidence for alternative evidence-based therapeutic strategies recognising that the therapeutic approach to PAH may vary depending on local availability (and expertise) of therapeutic options in various hospitals and clinical settings. In these tables, only the compounds officially approved for PAH or under regulatory approval process in at least one 


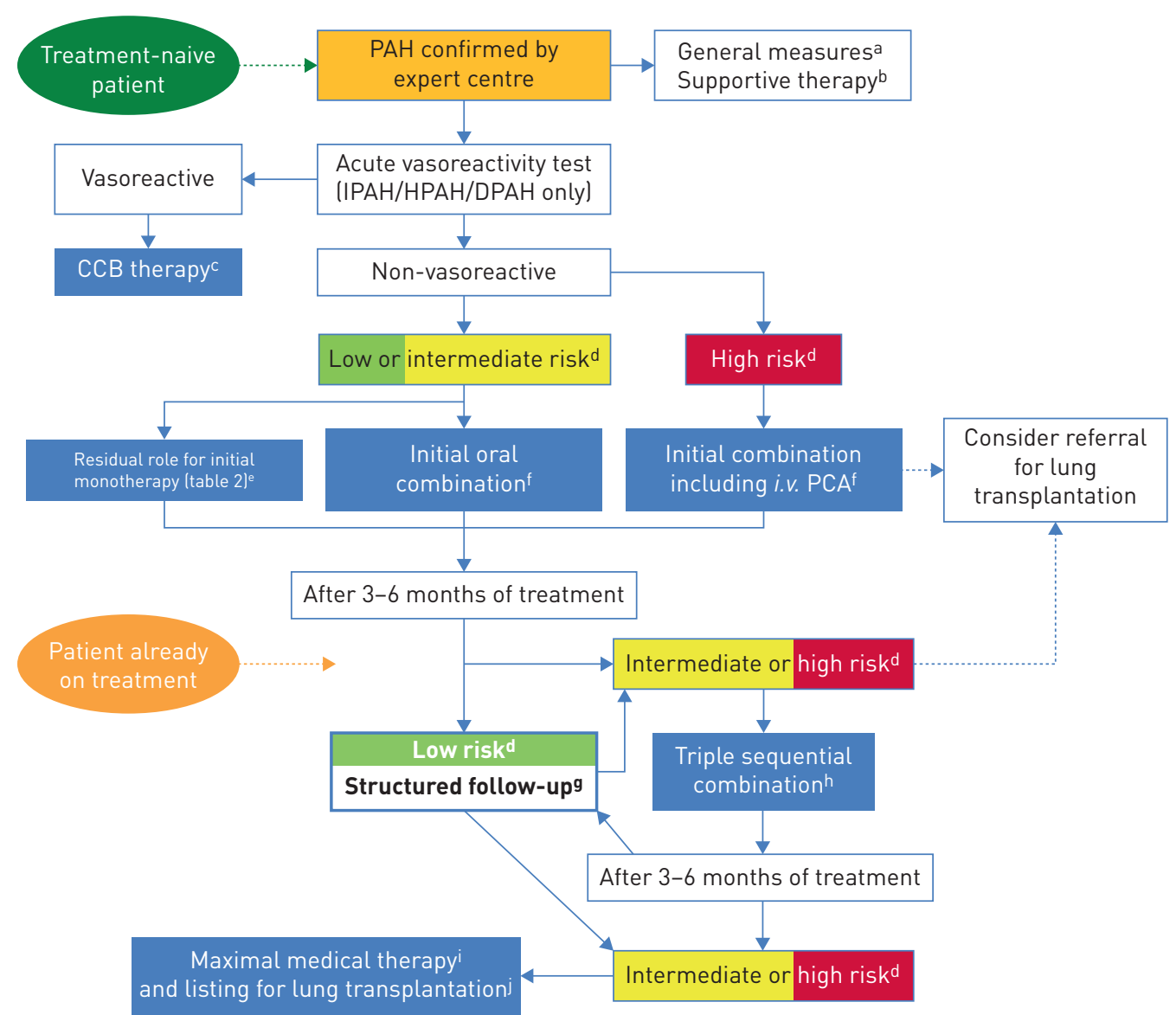

FIGURE 2 Treatment algorithm. PAH: pulmonary arterial hypertension; IPAH: idiopathic PAH; HPAH: heritable PAH; DPAH: drug-induced PAH; CCB: calcium channel blocker; PCA: prostacyclin analogue; PH: pulmonary hypertension. ${ }^{a}$ : 2015 ESC/ERS PH guidelines Table 16; ${ }^{b}: 2015$ ESC/ERS PH guidelines Table 17; ${ }^{c}: 2015$ ESC/ ERS PH guidelines Table 18; ${ }^{d}$ : 2015 ESC/ERS PH guidelines Table 13; ${ }^{\text {e: }} 2015$ ESC/ERS PH guidelines Table 19; ${ }^{\text {f: }} 2015$ ESC/ERS PH guidelines Table 20; ${ }^{\text {g: }} 2015$ ESC/ERS PH guidelines Table 14; ${ }^{\text {h: }} 2015$ ESC/ERS PH guidelines Table $21 ;$ i : maximal medical therapy is considered triple combination therapy including a s.c. or an i.v. PCA (i.v. preferred in high-risk status); ' 2015 ESC/ERS PH guidelines Table 22.

country are included. A four-level hierarchy for end-points in RCT has been proposed by experts based on level of evidence regarding efficacy $[72,73]$. According to this hierarchy, drugs or combination of drugs with outcome as the primary end-point in RCTs or drugs with demonstrated reduction in all-cause mortality (prospectively defined) have been highlighted with a footnote in the 2015 ESC/ERS PH guidelines Tables 19-21.

Treatment algorithm description

See the treatment algorithm in figure 2.

\section{Initial approach}

- After confirmation of the diagnosis of the treatment-naive PAH patient in an expert centre, the suggested initial approach is the adoption of general measures and the initiation of supportive therapy (2015 ESC/ERS PH guidelines Tables 16 and 17).

- Acute vasoreactivity testing should be performed to predict response to calcium channel blocker (CCBs) only in patients with IPAH, HPAH, and PAH associated with drugs and toxin use. Vasoreactive patients (see the Task Force article by SimONNEAU et al. [79] in this issue of the European Respiratory Journal) should be treated with high doses (progressively titrated) of CCBs; adequate response should be confirmed after 3-6 months of treatment (2015 ESC/ERS PH guidelines Table 18). Adequate treatment response to high doses of CCBs is considered WHO FC I/II with sustained haemodynamic improvement (same or better than achieved in the acute test) after at least 1 year on CCBs only. Vasoreactive patients without an adequate treatment response to high doses of CCBs 
TABLE 2 Potential role for initial monotherapy in specific pulmonary arterial hypertension (PAH) subsets

IPAH, HPAH and drug-induced PAH patient responders to acute vasoreactivity tests and with WHO FC I/II and sustained haemodynamic improvement (same or better than achieved in the acute test) after at least 1 year on CCBs only

Long-term-treated historical $\mathrm{PAH}$ patients with monotherapy (>5-10 years) stable with low-risk profile

IPAH patients > 75 years old with multiple risk factors for heart failure with preserved LVEF (high blood pressure, diabetes mellitus, coronary artery disease, atrial fibrillation, obesity)

$\mathrm{PAH}$ patients with suspicion or high probability of pulmonary veno-occlusive disease or pulmonary capillary haemangiomatosis

Patients with PAH associated with HIV infection or portal hypertension or uncorrected congenital heart disease, as they were not included in RCTs of initial combination therapy

$\mathrm{PAH}$ patients with very mild disease (e.g. WHO FC I, PVR 3-4 WU, mPAP <30 mmHg, normal right ventricle at echocardiography) Combination therapy unavailable or contraindicated (e.g. severe liver disease)

IPAH: idiopathic PAH; HPAH: heritable PAH; CCB: calcium channel blocker; PAP: pulmonary arterial pressure; PVR: pulmonary vascular resistance; LVEF: left ventricular ejection fraction; RCT: randomised controlled trial; WHO: World Health Organization; FC: Functional Class; WU: Wood Units; mPAP: mean PAP

should be treated with approved PAH medications according to the non-vasoreactive patients' treatment strategy.

- Non-responders to acute vasoreactivity testing who are at low or intermediate risk should be treated with initial oral combination therapy with an ERA and a PDE5i (2015 ESC/ERS PH guidelines Table 20) [76, 80, 81].

- Some specific PAH subsets in which the efficacy/safety ratio of initial combination therapy is not established (table 2) should be treated with initial monotherapy.

Recommendations for initial monotherapy are reported in the 2015 ESC/ERS PH guidelines Table 19.

- If initial monotherapy is chosen, as head-to-head comparisons among different compounds are not available, no evidence-based first-line monotherapy can be proposed. The choice of drug may depend on a variety of factors, including approval status, labelling, route of administration, side-effect profile, potential interaction with background therapies, patient preferences, comorbidities, physician experience and cost.

- In non-vasoreactive and treatment-naive patients at high risk, initial combination therapy including i.v. PCAs is recommended (2015 ESC/ERS PH guidelines Table 20). Intravenous epoprostenol receives the strongest recommendation as it has reduced the 3-month rate of mortality in high-risk PAH patients also as monotherapy (2015 ESC/ERS PH guidelines Table 19) [82]. Alternative types of initial combination therapy may be considered (2015 ESC/ERS PH guidelines Table 20). Referral for lung transplantation should also be considered.

Follow-up therapy

- When the initial treatment approach results in a low-risk status within 3-6 months, the therapy should be continued and structured follow-up established (2015 ESC/ERS PH guidelines Table 14).

- When the initial treatment approach results in an intermediate-risk status, escalation to triple combination therapy is recommended according to the 2015 ESC/ERS PH guidelines Table 21 or to double combination in case monotherapy has been chosen. The combinations of macitentan and sildenafil [60], riociguat and bosentan [61], and selexipag and ERA and/or PDE5i [69] have the highest recommendation and evidence. PCAs should also be considered. The combination of riociguat and PDE5i is contraindicated [62]. Referral for lung transplantation should also be considered.

- When the initial treatment approach results in a high-risk status, maximal medical therapy including i.v. PCAs is recommended (2015 ESC/ERS PH guidelines Table 20). Referral for lung transplantation should also be considered.

- When the second treatment step results in the low-risk status within 3-6 months, the therapy should be continued and structured follow-up continued (2015 ESC/ERS PH guidelines Table 14). Referral for lung transplantation should also be considered according to local rules for organ allocation and average waiting time in the list.

- When the second treatment step results in an intermediate- or high-risk status, escalation to maximal medical therapy is recommended according to the 2015 ESC/ERS PH guidelines Table 21. Maximal medical therapy is considered to be triple combination therapy including a s.c. or an i.v. PCA (i.v. preferred in high-risk status). For patients on intermediate-risk status on double combination therapy with an ERA and a PDE5i or riociguat, the addition of selexipag should be considered [69]. For 
patients on triple combination therapy including selexipag who remain in the intermediate-risk group or progress to high risk, the substitution with s.c. or i.v. PCAs should be considered. Referral for lung transplantation should also be considered.

- Patients on follow-up with low-risk status who deteriorate to the intermediate- or high-risk group should be treated with double, triple or maximal combination therapy depending on the initial background treatment.

- We recommend consideration of lung transplantation in all patients on maximal triple combination therapy, with priority for those in intermediate- and high-risk groups, in accordance with local rules for organ allocation and average waiting time in the list (2015 ESC/ERS PH guidelines Table 22) (see the Task Force article by HoEper et al. [83] in this issue of the European Respiratory Journal).

- Advanced treatments for patients in severe right ventricular failure who are admitted to intensive care units are reported by HoEper et al. [83].

- Balloon atrial septostomy should be regarded as a palliative or bridging procedure in patients deteriorating despite maximal medical therapy.

\section{Transitions of PAH therapies}

Clinicians might consider transitioning from one PAH-specific therapy to another for a number of reasons, including improvement of the side-effect profile and convenience or compliance with therapy. In patients who are not meeting treatment goals, transitions are considered to escalate therapy and improve patient status. Occasionally, patients have an extraordinary response to therapy and transition to a less invasive therapy is considered. As much of the literature on this topic is retrospective, prospective but observational or prospective randomised but open label, we do not recommend this approach except in rare circumstances and under close expert care. One study showed that, in carefully selected patients, the transition from i.v. epoprostenol to i.v. treprostinil was achievable around $80 \%$ of the time [84]. Transition from parenteral epoprostenol to the thermostable form was generally achievable [84].

There have been conflicting outcomes in the transition from parenteral prostacyclins to inhaled or oral prostacyclins [84]. When discontinuation of bosentan is necessary due to liver function test elevations, transitioning to ambrisentan [85] or macitentan is safe.

In case of lack of efficacy, transition from selexipag or non-parenteral PCAs to s.c. or i.v. PCAs is recommended.

There is insufficient evidence to recommend transition from sildenafil or tadalafil to riociguat for improving efficacy [86]. An additional open-label, randomised study is currently ongoing on this issue (ClinicalTrials.gov identifier NCT02891850).

\section{PAH complications}

PAH-related hospitalisations which usually are associated with different types of complications are predictive of mortality in post hoc analyses of the SERAPHIN and GRIPHON studies [87]. Recommendations for the diagnosis and treatment of arrhythmias, haemoptysis and mechanical complications related to the dilatation of the pulmonary artery are already reported in the 2015 ESC/ERS PH guidelines [1, 2]. Recently, a study has reported a large series of PAH patients with angina or angina-like symptoms who underwent percutaneous coronary interventions with stenting due to severe left main coronary artery stenosis by extrinsic compression from a dilated pulmonary artery [88]. The favourable acute and long-term results of this procedure suggest increased awareness for this important and potentially catastrophic complication.

\section{Conclusions}

Assessment of the severity of the newly diagnosed PAH patient by a multiparametric risk stratification approach is utilised for defining a low-, intermediate- or high-risk status. According to the risk status, the multiple drugs approved for $\mathrm{PAH}$, interfering with the endothelin, $\mathrm{NO}$ and prostacyclin pathways, can be utilised with different strategies including monotherapy or combination therapies. Further treatment escalation is required in case low-risk status is not achieved in planned follow-up assessments. Low-risk patients should continue with the chosen therapy and be assessed accurately in a structured follow-up to timely identify possible deteriorations. Triple combination therapy and lung transplantation may be required in most advanced cases.

Conflict of interest: N. Galiè reports grants and personal fees from Actelion, Bayer, GSK and Pfizer, and personal fees from MSD, outside the submitted work. R.N. Channick reports grants and personal fees from Actelion and Bayer, and personal fees from Arena, outside the submitted work. R.P. Frantz reports steering committee membership and research funding from Actelion, data and safety monitoring board and adjudication committee membership for United 
Therapeutics, and advisory board work for Abbott and Arena, outside the submitted work. E. Grünig reports grants and personal fees from Actelion and Bayer/MSD, grants from GSK, and personal fees from Bial, OrPhaSwiss GmbH and Medscape, outside the submitted work. Z.C. Jing reports grants from the Chinese Academy of Medical Sciences, Beijing Natural Science Foundation and National Natural Science Foundation of China, during the conduct of the study; and personal fees from Actelion Pharmaceuticals, Bayer Healthcare Pharmaceuticals, GSK, Pfizer and United Therapeutics, outside the submitted work. O. Moiseeva has nothing to disclose. I.R. Preston reports grants and personal fees for consultancy from Actelion, Gilead and United Therapeutics, grants from Bayer, and personal fees for adjudication committee membership from Pfizer, during the conduct of the study; and grants and personal fees for consultancy from Acceleron, Liquidia and Arena, outside the submitted work. T. Pulido reports research grants from Actelion, Lilly, Reata Pharmaceuticals and Bayer, personal fees for advisory board membership, speaking and lectures from Actelion, personal fees for lectures from Bayer, personal fees for advisory board membership from GSK, personal fees for advisory board membership and lectures from Pfizer, outside the submitted work. Z. Safdar reports speaker bureau, consultation and institutional grants for clinical trials from Actelion Pharmaceutical, United Therapeutics Gilead Pharmaceuticals, Genetech, Boehringer Ingelheim and Bayer Pharmaceuticals, outside the submitted work. Y. Tamura reports grants from Nippon Shinyaku Co., Ltd, and grants and personal fees from Actelion Pharmaceuticals Japan Ltd, during the conduct of the study. V.V. McLaughlin reports grants and personal fees from Actelion, Acceleron, Arena and Bayer, grants from Gilead and Sonovie, and personal fees from Caremark and United Therapeutics, during the conduct of the study.

\section{References}

1 Galiè N, Humbert M, Vachiery JL, et al. 2015 ESC/ERS Guidelines for the diagnosis and treatment of pulmonary hypertension. Eur Heart J 2016; 37: 67-119.

2 Galiè N, Humbert M, Vachiery JL, et al. 2015 ESC/ERS Guidelines for the diagnosis and treatment of pulmonary hypertension. Eur Respir J 2015; 46: 903-975.

3 Humbert M, Guignabert C, Bonnet S, et al. Pathology and pathobiology of pulmonary hypertension: state of the art and research perspectives. Eur Respir J 2019; 53: 1801887.

4 Vonk Noordegraaf A, Chin KM, Haddad F, et al. Pathophysiology of the right ventricle and of the pulmonary circulation in pulmonary hypertension: an update. Eur Respir J 2019; 53: 1801900.

5 Galiè N, Seeger W, Naeije R, et al. Comparative analysis of clinical trials and evidence-based treatment algorithm in pulmonary arterial hypertension. J Am Coll Cardiol 2004; 43: 12 Suppl. S, S81-S88.

6 Kylhammar D, Kjellström B, Hjalmarsson C, et al. A comprehensive risk stratification at early follow-up determines prognosis in pulmonary arterial hypertension. Eur Heart J 2018; 39: 4175-4181.

7 Hoeper MM, Kramer T, Pan Z, et al. Mortality in pulmonary arterial hypertension: prediction by the 2015 European pulmonary hypertension guidelines risk stratification model. Eur Respir J 2017; 50: 1700740.

8 Boucly A, Weatherald J, Savale L, et al. Risk assessment, prognosis and guideline implementation in pulmonary arterial hypertension. Eur Respir J 2017; 50: 1700889.

9 Hoeper M, Pittrow D, Opitz C, et al. Risk assessment in pulmonary arterial hypertension. Eur Respir J 2018; 51: 1702606.

10 D'Alonzo GE, Barst RJ, Ayres SM, et al. Survival in patients with primary pulmonary hypertension. Results from a national prospective registry. Ann Intern Med 1991; 115: 343-349.

11 Humbert M, Sitbon O, Chaouat A, et al. Survival in patients with idiopathic, familial, and anorexigen-associated pulmonary arterial hypertension in the modern management era. Circulation 2010; 122: 156-163.

12 Humbert M, Sitbon O, Yaici A, et al. Survival in incident and prevalent cohorts of patients with pulmonary arterial hypertension. Eur Respir J 2010; 36: 549-555.

13 Thenappan T, Shah SJ, Rich S, et al. Survival in pulmonary arterial hypertension: a reappraisal of the NIH risk stratification equation. Eur Respir J 2010; 35: 1079-1087.

14 Thenappan T, Glassner C, Gomberg-Maitland M. Validation of the pulmonary hypertension connection equation for survival prediction in pulmonary arterial hypertension. Chest 2012; 141: 642-650.

15 Lee W-TN, Ling Y, Sheares KK, et al. Predicting survival in pulmonary arterial hypertension in the UK. Eur Respir J 2012; 40: 604-611.

16 Benza RL, Miller DP, Gomberg-Maitland M, et al. Predicting survival in pulmonary arterial hypertension: insights from the registry to evaluate early and long-term pulmonary arterial hypertension disease management (REVEAL). Circulation 2010; 122: 164-172.

17 Benza RL, Gomberg-Maitland M, Miller DP, et al. The REVEAL registry risk score calculator in patients newly diagnosed with pulmonary arterial hypertension. Chest 2012; 141: 354-362.

18 Benza RL, Miller DP, Foreman AJ, et al. Prognostic implications of serial risk score assessments in patients with pulmonary arterial hypertension: a Registry to Evaluate Early and Long-Term Pulmonary Arterial Hypertension Disease Management (REVEAL) analysis. J Heart Lung Transplant 2015; 34: 356-361.

19 Benza RL, Gomberg-Maitland M, Elliott CG, et al. Comparison of three assessment strategies as predictors of one-year survival in US pulmonary arterial hypertension (PAH) patients. Am J Respir Crit Care Med 2018; 197: A7649.

20 Kane GC, Maradit-Kremers H, Slusser JP, et al. Integration of clinical and hemodynamic parameters in the prediction of long-term survival in patients with pulmonary arterial hypertension. Chest 2011; 139: 1285-1293.

21 Sitbon O, Benza RL, Badesch DB, et al. Validation of two predictive models for survival in pulmonary arterial hypertension. Eur Respir J 2015; 46: 152-164.

22 Farber HW, Miller DP, Poms AD, et al. Five-year outcomes of patients enrolled in the REVEAL Registry. Chest 2015; 148: 1043-1054.

23 Frantz RP, Farber HW, Badesch DB, et al. Baseline and serial brain natriuretic peptide level predicts 5-year overall survival in patients with pulmonary arterial hypertension: data from the REVEAL Registry. Chest 2018; 154: 126-135.

24 Chakinala MM, Coyne DW, Benza RL, et al. Impact of declining renal function on outcomes in pulmonary arterial hypertension: a REVEAL registry analysis. J Heart Lung Transplant 2018; 37: 696-705.

25 Frost AE, Badesch DB, Miller DP, et al. Evaluation of the predictive value of a clinical worsening definition using 2 -year outcomes in patients with pulmonary arterial hypertension. Chest 2013; 144: 1521-1529. 
26 Cogswell R, Pritzker M, De Marco T. Performance of the REVEAL pulmonary arterial hypertension prediction model using non-invasive and routinely measured parameters. J Heart Lung Transplant 2014; 33: 382-387.

27 Galiè N, Jansa P, Pulido T, et al. SERAPHIN haemodynamic substudy: the effect of the dual endothelin receptor antagonist macitentan on haemodynamic parameters and NT-proBNP levels and their association with disease progression in patients with pulmonary arterial hypertension. Eur Heart J 2017; 38: 1147-1155.

28 Dardi F, Palazzini M, Gotti E, et al. Simplified table for risk stratification in patients with different types of pulmonary arterial hypertension. 2018. https://esc365.escardio.org/Congress/ESC-Congress-2018/Poster-Session5-Right-heart-failure-in-pulmonary-hypertension/178843-simplified-table-for-risk-stratification-in-patients-withdifferent-types-of-pulmonary-arterial-hypertension\#abstract Date last accessed: October 16, 2018.

29 Weatherald J, Sitbon O, Humbert M. Validation of a risk assessment instrument for pulmonary arterial hypertension. Eur Heart J 2018; 38: 4182-4185.

30 Rubin LJ, Mendoza J, Hood M, et al. Treatment of primary pulmonary hypertension with continuous intravenous prostacyclin (epoprostenol). Results of a randomized trial. Ann Intern Med 1990; 112: 485-491.

31 Barst RJ, Rubin LJ, Long WA, et al. A comparison of continuous intravenous epoprostenol (prostacyclin) with conventional therapy for primary pulmonary hypertension. The Primary Pulmonary Hypertension Study Group. N Engl J Med 1996; 334: 296-302.

32 Badesch DB, Tapson VF, McGoon MD, et al. Continuous intravenous epoprostenol for pulmonary hypertension due to the scleroderma spectrum of disease. A randomized, controlled trial. Ann Intern Med 2000; 132: 425-434.

33 Galiè N, Humbert M, Vachiéry JL, et al. Effects of beraprost sodium, an oral prostacyclin analogue, in patients with pulmonary arterial hypertension: a randomised, double-blind placebo-controlled trial. J Am Coll Cardiol 2002; 39: 1496-1502.

34 Barst RJ, McGoon M, McLaughlin VV, et al. Beraprost therapy for pulmonary arterial hypertension. J Am Coll Cardiol 2003; 41: 2125.

35 Olschewski H, Simonneau G, Galiè N, et al. Inhaled iloprost in severe pulmonary hypertension. N Engl J Med 2002; 347: 322-329.

36 Channick RN, Simonneau G, Sitbon O, et al. Effects of the dual endothelin-receptor antagonist bosentan in patients with pulmonary hypertension: a randomised placebo-controlled study. Lancet 2001; 358: 1119-1123.

37 Rubin LJ, Badesch DB, Barst RJ, et al. Bosentan therapy for pulmonary arterial hypertension. N Engl J Med 2002; 346: 896-903.

38 Simonneau G, Barst RJ, Galiè N, et al. Continuous subcutaneous infusion of treprostinil, a prostacyclin analogue, in patients with pulmonary arterial hypertension. A double-blind, randomized, placebo-controlled trial. Am J Respir Crit Care Med 2002; 165: 800-804.

39 Langleben D, Christman BW, Barst RJ, et al. Effects of the thromboxane synthetase inhibitor and receptor antagonist terbogrel in patients with primary pulmonary hypertension. Am Heart J 2002; 143: E4.

40 Sastry BKS, Narasimhan C, Reddy NK, et al. Clinical efficacy of sildenafil in primary pulmonary hypertension: a randomized, placebo-controlled, double-blind, crossover study. J Am Coll Cardiol 2004; 43: 1149-1153.

41 Humbert M, Barst RJ, Robbins IM, et al. Combination of bosentan with epoprostenol in pulmonary arterial hypertension: BREATHE-2. Eur Respir J 2004; 24: 353-359.

42 Barst RJ, Langleben D, Frost A, et al. Sitaxsentan therapy for pulmonary arterial hypertension. Am J Respir Crit Care Med 2004; 169: 441-447.

43 Galiè N, Ghofrani HA, Torbicki A, et al. Sildenafil citrate therapy for pulmonary arterial hypertension. $N$ Engl J Med 2005; 353: 2148-2157.

44 Wilkins MR, Paul GA, Strange JW, et al. Sildenafil versus Endothelin Receptor Antagonist for Pulmonary Hypertension (SERAPH) study. Am J Respir Crit Care Med 2005; 171: 1292-1297.

45 Hoeper M, Leuchte $\mathrm{H}$, Halank $\mathrm{M}$, et al. Combining inhaled iloprost with bosentan in patients with idiopathic pulmonary arterial hypertension. Eur Respir J 2006; 4: 691-694.

46 McLaughlin VV, Oudiz RJ, Frost A, et al. Randomized study of adding inhaled iloprost to existing bosentan in pulmonary arterial hypertension. Am J Respir Crit Care Med 2006; 174: 1257-1263.

47 Galiè N, Beghetti M, Gatzoulis MA, et al. Bosentan therapy in patients with Eisenmenger syndrome: a multicenter, double-blind, randomized, placebo-controlled study. Circulation 2006; 114: 48-54.

48 Singh T, Rohit M, Grover A, et al. A randomized, placebo-controlled, double-blind, crossover study to evaluate the efficacy of oral sildenafil therapy in severe pulmonary artery hypertension. Am Heart J 2006; 151: 851.e1-851.e5.

49 Barst RJ, Langleben D, Badesch D, et al. Treatment of pulmonary arterial hypertension with the selective endothelin-A receptor antagonist sitaxsentan. J Am Coll Cardiol 2006; 47: 2049-2056.

50 Simonneau G, Rubin L, Galiè N, et al. Addition of sildenafil to long-term intravenous epoprostenol therapy in patients with pulmonary arterial hypertension. Ann Intern Med 2008; 149: 521-530.

51 Galiè N, Olschewski H, Oudiz RJ, et al. Ambrisentan for the treatment of pulmonary arterial hypertension. Results of the ambrisentan in pulmonary arterial hypertension, randomized, double-blind, placebo-controlled, multicenter, efficacy (ARIES) study 1 and 2. Circulation 2008; 117: 3010-3019.

52 Galiè N, Rubin LJ, Hoeper $\mathrm{M}$, et al. Treatment of patients with mildly symptomatic pulmonary arterial hypertension with bosentan (EARLY study): a double-blind, randomised controlled trial. Lancet 2008; 371: 2093-2100

53 Galiè N, Brundage BH, Ghofrani HA, et al. Tadalafil therapy for pulmonary arterial hypertension. Circulation 2009; 119: 2894-2903.

54 Iversen K, Jensen AS, Jensen TV, et al. Combination therapy with bosentan and sildenafil in Eisenmenger syndrome: a randomized, placebo-controlled, double-blinded trial. Eur Heart J 2010; 31: 1124-1131.

55 McLaughlin V, Rubin L, Benza RL, et al. Addition of inhaled treprostinil to oral therapy for pulmonary arterial hypertension: a randomized controlled clinical trial. J Am Coll Cardiol 2010; 55: 1915-1922.

56 Ghofrani HA, Morrell NW, Hoeper MM, et al. Imatinib in pulmonary arterial hypertension patients with inadequate response to established therapy. Am J Respir Crit Care Med 2010; 182: 1171-1177.

57 Tapson VF, Torres F, Kermeen F, et al. Oral treprostinil for the treatment of pulmonary arterial hypertension in patients on background endothelin receptor antagonist and/or phosphodiesterase type 5 inhibitor therapy (the FREEDOM-C study): a randomized controlled trial. Chest 2012; 142: 1383-1390. 
58 Simonneau G, Torbicki A, Hoeper MM, et al. Selexipag, an oral, selective prostacyclin receptor agonist for the treatment of pulmonary arterial hypertension. Eur Respir J 2012; 40: 874-880.

59 Jing ZC, Yu ZX, Shen JY, et al. Vardenafil in pulmonary arterial hypertension: a randomized, double-blind, placebo-controlled study. Am J Respir Crit Care Med 2011; 183: 1723-1729.

60 Pulido T, Adzerikho I, Channick RN, et al. Macitentan and morbidity and mortality in pulmonary arterial hypertension. N Engl J Med 2013; 369: 809-818.

61 Ghofrani HA, Galiè N, Grimminger F, et al. Riociguat for the treatment of pulmonary arterial hypertension. N Engl J Med 2013; 369: 330-340.

62 Galiè N, Muller K, Scalise AV, et al. PATENT PLUS: a blinded, randomised and extension study of riociguat plus sildenafil in PAH. Eur Respir J 2015; 45: 1314-1322.

63 Hoeper MM, Barst RJ, Bourge RC, et al. Imatinib mesylate as add-on therapy for pulmonary arterial hypertension: results of the randomized IMPRES study. Circulation 2013; 127: 1128-1138.

64 Zhuang Y, Jiang B, Gao H, et al. Randomized study of adding tadalafil to existing ambrisentan in pulmonary arterial hypertension. Hypertens Res 2014; 37: 507-512.

65 Tapson VF, Jing ZC, Xu KF, et al. Oral treprostinil for the treatment of pulmonary arterial hypertension in patients on background endothelin receptor antagonist and/or phosphodiesterase type 5 inhibitor therapy (the FREEDOM-C2 study): a randomized controlled trial. Chest 2013; 144: 952-958.

66 Jing ZC, Parikh K, Pulido T, et al. Efficacy and safety of oral treprostinil monotherapy for the treatment of pulmonary arterial hypertension: a randomized, controlled trial. Circulation 2013; 127: 624-633.

67 Galiè N, Barbera JA, Frost AE, et al. Initial use of ambrisentan plus tadalafil in pulmonary arterial hypertension. N Engl J Med 2015; 373: 834-844.

68 McLaughlin V, Channick RN, Ghofrani HA, et al. Bosentan added to sildenafil therapy in patients with pulmonary arterial hypertension. Eur Respir J 2015; 46: 405-413.

69 Sitbon O, Channick R, Kelly C, et al. Selexipag for the treatment of pulmonary arterial hypertension. $N$ Engl J Med 2015; 373: 2522-2533.

70 Galiè N, Palazzini M, Manes A. Pulmonary arterial hypertension: from the kingdom of the near-dead to multiple clinical trial meta-analyses. Eur Heart J 2010; 31: 2080-2086.

71 McLaughlin VV, Badesch DB, Delcroix M, et al. End points and clinical trial design in pulmonary arterial hypertension. J Am Coll Cardiol 2009; 54: 1 Suppl., S97-S107.

72 Fleming TR. Surrogate endpoints and FDA accelerated approval process. Health Aff 2005; 24: 67-78.

73 Fleming TR, Powers JH. Biomarkers and surrogate endpoints in clinical trials. Statist Med 2012; 31: 2973-2984.

74 Galiè N, Manes A, Negro L, et al. A meta-analysis of randomized controlled trials in pulmonary arterial hypertension. Eur Heart J 2009; 30: 394-403.

75 Lajoie AC, Lauziere G, Lega JC, et al. Combination therapy versus monotherapy for pulmonary arterial hypertension: a meta-analysis. Lancet Respir Med 2015; 4: 291-305.

76 Hassoun PM, Zamanian RT, Damico R, et al. Ambrisentan and tadalafil up-front combination therapy in scleroderma-associated pulmonary arterial hypertension. Am J Respir Crit Care Med 2015; 192: 1102-1110.

77 Ehlken N, Lichtblau M, Klose H, et al. Exercise training improves peak oxygen consumption and hemodynamics in patients with severe pulmonary arterial hypertension and inoperable chronic thromboembolic pulmonary hypertension - a prospective, randomized, controlled trial. Eur Heart J 2015; 37: 35-44.

78 Keusch S, Turk A, Saxer S, et al. Rehabilitation in patients with pulmonary arterial hypertension. Swiss Med Wkly 2017; 147: w14462.

79 Simonneau G, Montani D, Celermajer DS, et al. Haemodynamic definitions and updated clinical classification of pulmonary hypertension. Eur Respir J 2019; 53: 1801913.

80 Galiè N, Barbera JA, Frost A, et al. AMBITION: a randomised, multicenter study of first-line ambrisentan and tadalafil combination therapy in subjects with pulmonary arterial hypertension (PAH). Eur Respir J 2014; 44: 2916.

81 Sitbon O, Sattler C, Bertoletti L, et al. Initial dual oral combination therapy in pulmonary arterial hypertension. Eur Respir J 2016; 47: 1727-1736.

82 Galiè N, Corris P, Frost A, et al. Updated treatment algorithm of pulmonary hypertension. J Am Coll Cardiol 2013; 62: D60-D72.

83 Hoeper MM, Benza RL, Corris P, et al. Intensive care, right ventricular support and lung transplantation in patients with pulmonary hypertension. Eur Respir J 2019; 53: 1801906.

84 Sofer A, Ryan MJ, Tedford RJ, et al. A systematic review of transition studies of pulmonary arterial hypertension specific medications. Pulm Circ 2017; 7: 326-338.

85 McGoon M, Frost A, Oudiz R, et al. Ambrisentan therapy in patients with pulmonary arterial hypertension who discontinued bosentan or sitaxsentan due to liver function test abnormalities. Chest 2009; 135: 122-129.

86 Hoeper MM, Simonneau G, Corris PA, et al. RESPITE: switching to riociguat in pulmonary arterial hypertension patients with inadequate response to phosphodiesterase-5 inhibitors. Eur Respir J 2017; 50: 1602425.

87 McLaughlin VV, Hoeper MM, Channick RN, et al. Pulmonary arterial hypertension-related morbidity is prognostic for mortality. J Am Coll Cardiol 2018; 71: 752-763.

88 Galiè N, Saia F, Palazzini M, et al. Left main coronary artery compression in patients with pulmonary arterial hypertension and angina. J Am Coll Cardiol 2017; 69: 2808-2817. 